\title{
GREEN URBAN INTERCHANGES: STAKEHOLDER AND USER PERSPECTIVES
}

\author{
Eftihia Nathanail ${ }^{1}$, Giannis Adamos ${ }^{2}$, Maria Tsami $^{3}$, Irina Yatskiv (Jackiva) ${ }^{4}$ \\ ${ }^{1}$ University of Thessaly, Department of Civil Engineering \\ Pedion Areos, GR-38334 Volos, Greece \\ Ph.: +302421074164, Fax: +302421074131, E-mail: enath@uth.gr \\ ${ }^{2}$ University of Thessaly, Department of Civil Engineering \\ Pedion Areos, GR-38334 Volos, Greece \\ Ph.:+302421074158,Fax:+302421074131,E-mail: giadamos@civ.uth.gr \\ ${ }^{3}$ University of Thessaly, Department of Civil Engineering \\ Pedion Areos, GR-38334 Volos, Greece \\ Ph.: +302421074133, Fax: +302421074131, E-mail: marttsami@ gmail.com \\ ${ }^{4}$ Transport and Telecommunication Institute \\ Lomonosova Street 1, LV-1019 Riga, Latvia \\ Ph.: +37167100544, Fax:+37167100660, E-mail: Jackiva.I@tsi.lv
}

\begin{abstract}
The present paper aims at analysing the concept of "urban interchanges" as a solution towards seamless transportation and sustainable mobility. Based on an extensive review of policies, initiatives and data analysis coming from interviews and meetings with stakeholders, a coherent interchange design typology was formulated that links seamless transport and urban interchanges to spatial and urban planning. Focusing on the impact of user satisfaction as a priority towards user travel choices, a list of indicators was valuated. The comparative analysis of interchange typology performance formulated by the users' perception regarding netw ork accessibility, surrounding area, offered interchange time facilities and environmentally friendly services and infrastructure revealed fruitful findings on proper interchange design towards sustainability and reformation of the city-hubs into true green urban interchanges.
\end{abstract}

Keywords: Urban mobility; city hubs; intermodal transportation; environment; urban planning; sustainability

\section{Introduction}

Transport has gradually become one of the main fields of concern of the European policy, with a continuous expanding scope for action. The White Paper "European transport policy for 2010: Time to decide" (European Commission, 2001) was the first comprehensive framework to achieve a sound European transport policy, in which the European Union (EU) exposed its vision for the next ten years, aiming at striking the balance between the economic development and the quality and safety demands of societies. At the same time, the White Paper stated that the common transport policy had to be part of an overall strategy for sustainable development, including economic policy, land-use planning policy, social education policy, urban transport policy at local level -especially in large cities-, budgetary and fiscal policy, competition policy and research policy. In 2006, the Mid-term review of White Paper, and the Communication "A sustainable future for transport: Towards an integrated, technology led and user friendly system" (European Commission, 2006) addressed the same transport policy objectives, and argued for a comprehensive, holistic approach to transport policy, considering that mutually complementary action is needed at national, regional and local levels of governance including industry and society.

Urban implications of mobility have also been of concern for the Communitarian Bodies that resulted in the Communication from the Commission to the European Parliament, the Council, the European Economic and Social Committee and the Committee of the Regions "Action Plan on Urban Mobility" (European Communities, 2009). In the context of this Communication, urbanisation and its impact on transport was identified as one of the key challenges in providing a more sustainable transportation system, through short and medium-term actions (from 2009 to 2012) that integrate urban mobility and promote partnerships at a local, regional and national level and enhance the involvement of EU stakeholders, especially in terms of communication between citizens and industry.

In addition, the most recent, published by the European Commission, 2011 White Paper "Roadmap to a Single European Transport Area - Towards a competitive and resource efficient transport system" (European Commission, 2011) considers three pillars of priorities; people, integration and 
technology. It includes objectives, actions and initiatives for the development of a more competitive and sustainable transport system till 2050, considers intermodal integration among the main quality characteristics of the future transport systems and foresees initiatives for the elimination of important obstacles and bottlenecks that obstruct the improvement and cohesion in key aspects of transport, i.e. infrastructure, investments, harmonization of legal frameworks, etc. As a follow-up to the 2011 White Paper, the European Commission came up in 2013 with the "Urban Mobility Package", which introduced the concept of "Sustainable Urban Mobility Plans" (SUMPs), as a result of the broad exchange of knowledge and experience between stakeholders and planning experts across the European Union (European Commission, 2013). The concept defines the basic characteristics that a modern and sustainable mobility and transport plan should include, and comprises the following elements: a) Goals and objectives, b) A long-term vision and clear implementation plan, c) An assessment of current and future performance, d) The balanced and integrated development of all modes, e) Horizontal and vertical integration, f) Participatory approach, g) Monitoring, review and reporting, and h) Quality assurance (European Commission, 2013).

The European Commission (EC) is in close cooperation with the Member States in order to ensure that the concept of "Sustainable Urban Mobility Plans" (SUMPs) is adapted to the specific requirements and existing practices in each Member State. Among the actions that the European Commission takes over for the enhancement of SUMPs is the support of the exchange of knowledge and practice on urban development through specific programs, such as the European Territorial Cooperation Programme "URBACT", which enables cities to work together for the development of solutions to major urban challenges. In addition, the EC, through the initiative "CIVITAS 2020", supports local partnerships in order to implement and test new urban mobility approaches under real-life conditions. Following the "Smart Cities and Communities Initiative", which was launched by the European Commission in 2011, the European Innovation Partnership for Smart Cities and Communities collaboration began in July 2012, which, combining Information and Communication Technologies, energy and transport management, aims at coming up with innovating solutions that can address the major environmental, societal and health challenges that European cities face.

Intermodal integration assumes that "different transportation modes are being combined in a trip, in order to achieve a seamless journey", with the aim of providing the means for better mobility and impact minimization. Such integration occurs mainly at transport interchanges, which can be defined as "transportation network nodes that enable seamless mobility, increase travelling efficiency, achieve user satisfaction and ensure system performance for door-to-door journey by making optimal use of combinations of modes in a sustainable way". Furthermore, urban transport interchanges may also be referred to as city-hubs.

Sintroper (2012) proposed three criteria for evaluating urban interchanges: sustainability, integration and technical design, represented by a number of components under each category. He underlined the emerging issue of developing sustainable transport interchanges as part of interchange design objectives, pointing out the fundamental role of soft modes promotion and usage. Edwards (2011) stated that "Transport interchange design offers many opportunities to enrich the public realm, to support social sustainability and to create conditions for the economic recovery of inner city areas". According to his research, the proper interchange design has to consider all modes of transport, especially when social sustainability is related to sustainable modes of transport.

The Presto project (2009-2012) came up with the finding that "All public transport stops must be considered as potential interchange points of the public transport networks and the cycle network", highlighting the necessity of proper cycling facilities at interchanges and the need to reform interchanges so as to accommodate cycling needs and promote soft modes of transport. Naude et al. (2005) focused on the needs of pedestrians when designing an interchange, considering the urban meaning of interchange and pursuing at the same time sustainable transport through investment in low cost forms of mobility.

\section{Methodological Approach}

The paper analyses the concept of "urban interchanges" in the context of spatial and urban planning, under three required elements for decision-making, developing, functioning and consequently evaluating the performance of an interchange: i) governance; ii) services; and iii) user needs and expectations (Adamos et al., 2015). The adopted methodology involves the following steps:

- Extensive review of policies and initiatives at a national and European level.

- Interviews and meetings with stakeholders who are involved in the decision making, design, construction and operation of urban transport interchanges and elaboration of the revealed findings. 
- User satisfaction survey and identification of gaps.

- Drawing of a list of guidelines based on "greening" intermodal mobility enablers of the future interchanges.

\section{The role of Urban Interchanges in Urban and Spatial Planning}

Reducing private transport use and increasing that of public transport seem to be two crucial but also challenging issues to be addressed when dealing with urban transportation. Urban passenger interchanges, firstly reviewed for Europe in 2000 in the GUIDE project (Sintropher, 2012), are strongly related to seamless public transport, and when they are efficiently designed and operated, they can facilitate all user requirements and enable seamless mobility, travelling efficiency, user satisfaction and performance.

Research has shown that currently there are few examples of policies, regulations or guidance that cover the design, construction, management and operation of interchanges as a whole. Often, the interchange facility and its catchment area (called interchange zone) are not considered satisfactorily in transport planning, while the roles and responsibilities of those involved or interested in the interchange are frequently dominated by the regulatory framework of each mode. In addition, studies have revealed that the link between urban interchanges and their impacts on land use are not direct, if there is not a strong integrated development plan associated to the involvement of policy makers (Edwards, 2011). In order to investigate how the urban interchanges are linked to urban and spatial planning, three elements are used (City-HUB, 2015):

- Governance, which incorporates the identification of the stakeholders (decision makers and providers) and users (travellers and visitors), and the definition of their roles, needs and methods for developing a cooperative scheme for coherent decision making;

- Services, which are related to the physical design, the transportation modes, the information provision at the interchange, as well as to the visitors' facilitation while staying at the interchange; and

- User needs and expectations in the interchange design and operation. These needs and expectations are usually addressed through surveys assessing users' perception of service quality.

These three elements contribute in the definition of seamless urban interchanges, as the upper layers of a pyramid, the base of which is the urban and spatial planning, which provides and foundation and sturdy support to the development and operation of these facilities (Fig. 1) (Adamos et al., 2015).

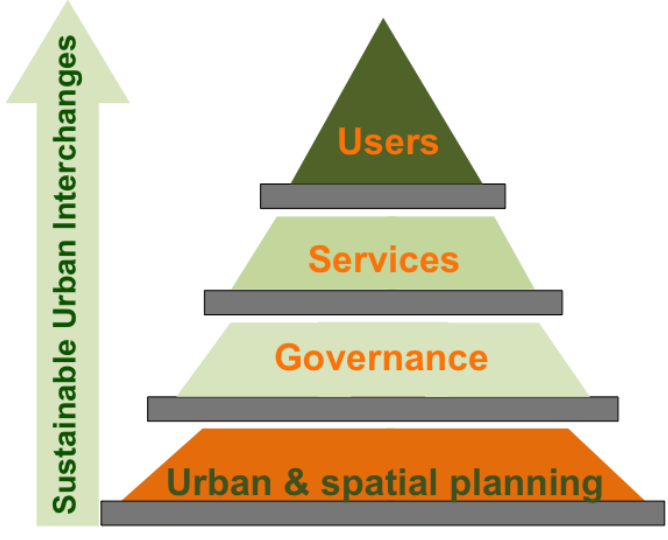

Figure 1. The pyramid of urban interchanges elements (Adamos et al., 2015)

\subsection{Governance}

In Greece, there is not a united regulatory framework regarding the design, construction and operation of interchanges, since the different modes at each interchange are regulated under different frameworks. The whole supervision of transport is under the Ministry of Infrastructure, Transport and Networks, which plans and implements national policy, establishes the relevant institutional framework at European and international scope for the integration of high quality transportation of passengers and goods, and ensures safety and security (www.yme.gr). The design, construction and operation of the different modes involved in each interchange, are developed under the relative national legislation, which is compliant to European and international directives. 
Specifically, it is foreseen that the implementation of EU regulations is obligatory for all membercountries, without any integration in national legislation, whereas the implementation of Directives, even though it is obligatory, first needs to be integrated in the national legislation, while adoption of the rest legislative acts (opinions, actions, positions, etc.) is not obligatory for national legal frameworks. Towards this direction, the regulatory framework for each mode involved in an interchange is developed separately.

As of currently, the most representative ownership scheme in public transport foresees that the interurban transport structure is private (companies limited by shares), while the local public transport operations are under the supervision of legal non-profit entities organised under private laws, assisted with concession agreements that are signed between the Greek government and the operators. In the case that rail is an involved mode at the interchange the relevant operations are performed by the public Organisation of Hellenic Railways and its independent public companies. Other private bodies are also involved in the management and operation of specific functions of the interchange, and mainly are responsible for the provision of services to travellers, i.e. taxi companies, parking facilities.

\subsection{Services}

Services at an interchange are strongly related to its size, and affect the quality and success of the interchange. Apart from the size of the interchange, the number of different transportation modes and the location also affect the level of services provided, and in turn these two elements affect the number of different stakeholders involved in the decision making processes, operation and maintenance, and eventually the local impacts of the interchange.

Part of the services contain the provision of information to travellers, an issue addressed in Greece by references included in the public transport (bus) and rail legislation, mainly through the use of telematics. Time table integration and scheduling flexibility and adaptability are not addressed in the legal and organizational framework of the interchange, and rely on bilateral agreements for cooperative schemes and collaboration among service providers and operators.

When designing an interchange it is important to consider the most appropriate use of space, when deciding the number and type of facilities that should be included. The types of facilities included in an interchange depend on the scope of the interchange, and apart from basic facilities, such as shelter, seating, toilets, kiosks, tickets and information desks, a number of additional services should be offered, like wide range of retail options, catering and other, incorporated into a shopping centre inside the interchange.

In parallel, the fitting of the interchange to the surrounding environment should also be considered and the respective design should be structured in a way that links successfully the interchange with local networks and destinations. Finally, the external environment in the surrounding of the interchange has also a significant impact on possible retail business development, supporting the local economy and other social activities of the city.

\subsection{Users}

Interchange users are distinguished in travellers and non-travellers (visitors) (City-HUB, 2015). Each of these groups has its own objectives and requirements for the services provided at the interchange. Travellers' requirements and decision made about the trip depend on their personal characteristics and mobility needs. When passing through an interchange, travellers usually have to wait and spend time. In general their expectation for the interchange can be expressed in timesavings and convenient, comfortable and safe modal changes. Thus, the requirements focus around the availability of services that facilitate seamless travel. In addition, commuters generally want to travel as quickly as possible, whereas leisure travellers are less reluctant to long waiting times at interchanges. When other services, besides the transportation function itself, are offered, or shops are located at the interchange, the quality of the waiting time may improve, and the interchange can be more attractive even to non-travellers, who can do every day business at the facility.

\section{Selection of Interchanges}

Starting point for this research was the City-HUB European project (2015), where several interchanges/terminals were surveyed and their practitioners were interviewed all around Europe. In Greece, the surveys were done to stakeholders and users of selected transportation interchanges. Four interchanges were selected based on the following criteria: 
- Geographical coverage of the country: The interchanges are located in the vicinity of metropolitan areas, big cities and small to medium size cities.

- Urban-interurban interconnection: All interchanges accommodate interconnection between long distance travelling, mainly national, and urban trips.

- Transportation modes availability: Railway and road transportation are being covered by the selected interchanges. Three of them interface interurban coach service and urban transit, and one railway, interurban coach and urban transit.

- Location variability: The interchanges are located either in the wider city centre, the city limits or the suburban area, depending also on the size of the city they accommodate.

The Greek urban interchanges that participated in this research are the following (Adamos et al., 2015):

- Intercity Coaches of Magnesia, Volos

- Macedonia Coach, Thessaloniki

- KTEL Kifisou, Athens

- New Railway, Thessaloniki

\subsection{Intercity coaches of Magnesia Interchange, Volos}

The Intercity Coaches of Magnesia Interchange opened in the decade of 1970 and an entire redevelopment took place in 1990s, including the refurbishment of the waiting and ticketing area, the storage and the offices. It is located in the urban area of Volos, very close to the local buses terminal (50 meters) and the School of Engineering of the city's university (100 meters). The railway station and the port are also close enough at 1.5 and 2 kilometres, respectively. In the surrounding area of the interchange, apart from the university campuses, catering and coffee shops, and restaurant street markets may be found. Housing development is average and population density low. The interchange has an ascending role in the overall transportation network, since it provides travelling services between Volos and 9 big cities out of Magnesia, 36 destinations in Magnesia, and connection from and to the airport of Aghialos. Taxis are available right outside the main building and car and bicycle parking facilities are also provided, adjacently to the interchange. The connectivity with both the urban and interurban transportation modes is considered adequate (Adamos et al., 2015).

\subsection{Macedonia Coach Interchange, Thessaloniki}

The Macedonia Coach Interchange is one of the largest in Greece. It opened in September 2002 and is located in the suburban area of the city of Thessaloniki, $5 \mathrm{~km}$ west of the city centre. It is at a strategic junction of three main arterial roads. The interchange serves local, national and international trips. Local public transport interconnects the interchange with the city of Thessaloniki. Additionally, national trips are possible since scheduled bus routes connect the city of Thessaloniki with 41 Greek cities. Finally, international connections to Bulgaria (Sofia) and Albania (Tirana) are scheduled on a daily basis (Adamos et al., 2015).

\subsection{KTEL Kifisou Interchange, Athens}

KTEL Kifisou Interchange is located in the Metropolitan Area of the capital city of Greece and is one of the major interchanges in the country for interurban transportation of passengers and goods. The terminal opened in 1971 and underwent some general refurbishment in 2003. This included replacing of the roof protecting the buses, repainting of the building, some interior design work and provision of facilities for people with mobility special needs. The interchange accommodates local (urban-interurban) and national (interurban-interurban) travelling and connects Athens with most of the destinations nationwide, directly or with transfer. Also, there is connectivity with taxi services and city buses at the vicinity of the interchange (Adamos et al., 2015).

\subsection{New Railway Interchange, Thessaloniki}

The New Railway Interchange of Thessaloniki accommodates railway passengers who travel between the city and the suburban area, national and international destinations. It is located in the urban area of the city, close to the "Western Exit" Highway. Apart from the railway, the interchange serves as one of the two bus terminals in the city, for urban and suburban trips. The new metro terminal, currently being constructed, is also located at the New Railway Interchange. The on-going works play a catalytic role in the transformation of the facility, which will turn into a major transportation interchange for intermodal travelling, providing, a new underground parking and new walking and cycling facilities. The new project is 
expected to highly affect the surrounding area, providing more incentives for new businesses, attracting housing relocation and increasing land and property value in the area. The facility is situated very close to the central business district, allowing the movement of travellers all around the city. It is also close to the port of Thessaloniki, enhancing the attractiveness of the interchange (Adamos et al., 2015).

\section{Assessment of Interchanges Design Attributes}

Actors involved in the interchange design and operation were distinguished in two categories. The first category comprises the stakeholders, who are involved in the decision making at a strategic or operational stage, the service providers and the operators. The second category consists of the users who use the interchange either to travel (travellers) or to visit some amenities offered at the interchange, and are not relevant to travelling (non-travellers).

Assessment of the interchange was conducted taking into account stakeholders' and users' perspective.

\subsection{Stakeholders' views}

Urban transport interchanges in many European cities are often designed to service different scale functions, which in turn address new hierarchies in urban development, land uses, society, jobs, housing and environment within cities and consequently affect the urban and spatial planning of a city.

For the purpose of the present research, interviews and meetings were scheduled with stakeholders who are involved in the decision making, design, construction and operation of urban transport interchanges. Practitioners were either from business community, local authorities, or transport providers. At each interchange 2-5 stakeholders were interviewed, depending on the different roles they are associated with. The interview covered topics such as the interchange background, the regulatory, ownership and management structures, financing, public consultation, reasons for success and key factors in the design, methods or guidelines used to help co-ordination, energy efficiency and air quality, impacts on employment, housing, retail, etc., impacts on local economy and land use planning. Operational issues related to information and integration of information systems, ticketing and other intelligent transport services, are not within the context of the present analysis, and thus not presented here.

A typology was developed as depicting the impacts of interchanges on urban development and the environment, based on a set of indicators, as presented in Table 1, referring to the scope of the interchange, the demand and supply, the land uses and the sustainable design attributes. The typology was applied to the four Greek case studies described above, and the results of the interviews and meetings with their stakeholders are given in Table 1:

Table 1. Stakeholders' assessment of the interchanges design attributes towards urban development and environment (Adamos et al., 2015)

\begin{tabular}{|c|c|c|c|c|}
\hline \multirow[b]{2}{*}{ Indicator } & \multicolumn{4}{|c|}{ Interchange } \\
\hline & $\begin{array}{c}\text { Intercity Coaches of } \\
\text { Magnesia }\end{array}$ & Macedonia Coach & KTEL Kifisou & New Railway \\
\hline \multicolumn{5}{|l|}{ Role in the network } \\
\hline Local & Yes & Yes & Yes & Yes \\
\hline Regional & Yes & Yes & Yes & Yes \\
\hline National & Yes & Yes & Yes & Yes \\
\hline International & No & Yes & No & No \\
\hline Number of transport modes & 8 & 4 & 5 & 9 \\
\hline Daily passengers & $\begin{array}{c}\text { 689,197 passengers } \\
\text { (yearly) }\end{array}$ & $20,000-25,000$ & $25,000-27,000$ & 166,601 \\
\hline Integrated development plan & No & No & No & No \\
\hline Integrated shopping mall & No & No & No & Yes \\
\hline Nearby shopping & Yes & No & Yes $\left(50,000 \mathrm{~m}^{2}\right)$ & Yes \\
\hline New housing & No & No & No & No \\
\hline New offices & No & No & No & No \\
\hline Direct \& indirect jobs & 200 & 100 & - & - \\
\hline Energy efficiency measures & Natural gas use & - & $\begin{array}{l}\text { Coaches fleet } \\
\text { with lower } \\
\text { emissions }\end{array}$ & $\begin{array}{l}\text { Lighting and air- } \\
\text { conditioning } \\
\text { Energy strategy plan } \\
\text { Greener bus fleet }\end{array}$ \\
\hline
\end{tabular}


In Table 1, it appears that the interchanges play an important role at the local, regional and national and international context. This means that coordination and cooperation among actors is a requisite, which becomes even more demanding, as usually many transportation modes need to be accommodated at the same facility. However, in the current situation, none of these terminals has been actually designed as an interchange, and all respective operations adjust to the needs of the travellers. Consequently, all coordination and cooperation schemes remain to the level of management and operation of the interchange, and do not involve spatial planning principles; thus, the interaction of the interchanges with the surrounding area is low and circumstantial. Concerning their sustainability, interchanges contribute to lower emissions, only from the side of the operators, which reveals a gap of the facilities' sustainable design.

\subsection{Users' perspectives}

To address design gaps in terms of sustainability from the perspective of the users, an internetbased survey questionnaire was developed and implemented at two out of four interchanges, the New Railway Interchange and the intercity Coaches of Magnesia.

The sample was counted to 223 users. Participants were asked to evaluate the existing conditions at the interchange by grading the above indicators on a 5-point scale ranging from 1 (poor) to 5 (excellent), with the additional options DK/NA standing for "Don't Know/Not Answer" and "Not present".

For the scope of this research and for comparing stakeholder views and user perspectives, a selection of the questionnaire indicators was made, as shown in Table 2. Table 2 presents the status of the interchanges, as stated by the stakeholders and user satisfaction in relation to urban development and environment.

Table 2. Users' assessment of the interchange design attributes towards urban development and environment

\begin{tabular}{|c|c|c|c|c|c|c|}
\hline \multirow[b]{2}{*}{$\begin{array}{l}\text { Indicator (for } \\
\text { stakeholders) }\end{array}$} & \multicolumn{2}{|c|}{ Interchange } & \multirow[b]{2}{*}{$\begin{array}{l}\text { User indicator } \\
\text { category }\end{array}$} & \multirow[b]{2}{*}{$\begin{array}{l}\text { Indicator (for } \\
\text { users) }\end{array}$} & \multicolumn{2}{|l|}{ Interchange } \\
\hline & $\begin{array}{l}\text { Intercity } \\
\text { Coaches of } \\
\text { Magnesia }\end{array}$ & $\begin{array}{l}\text { New } \\
\text { Railway }\end{array}$ & & & $\begin{array}{l}\text { Intercity } \\
\text { Coaches of } \\
\text { Magnesia }\end{array}$ & $\begin{array}{l}\text { New } \\
\text { Railway }\end{array}$ \\
\hline \multirow[b]{2}{*}{ Role in network } & \multirow{2}{*}{$\begin{array}{l}\text { Local, } \\
\text { regional, } \\
\text { national }\end{array}$} & \multirow{2}{*}{$\begin{array}{l}\text { Local, } \\
\text { regional, } \\
\text { national }\end{array}$} & \multirow{2}{*}{$\begin{array}{l}\text { Network } \\
\text { accessibility }\end{array}$} & Ease of access & 3.71 & 2.86 \\
\hline & & & & $\begin{array}{l}\text { Distances between } \\
\text { modes }\end{array}$ & 3.75 & 3.04 \\
\hline \multirow{3}{*}{$\begin{array}{l}\text { Integrated } \\
\text { shopping mall }\end{array}$} & \multirow{3}{*}{ No } & \multirow{3}{*}{ Yes } & \multirow{3}{*}{ Interchange time } & Use of time & 3.11 & 2.27 \\
\hline & & & & $\begin{array}{l}\text { Number and variety } \\
\text { of shops }\end{array}$ & Not present & 2.48 \\
\hline & & & & $\begin{array}{l}\text { Number and variety } \\
\text { of coffee shops and } \\
\text { restaurants }\end{array}$ & 2.32 & 2.48 \\
\hline Nearby shopping & Yes & Yes & Surrounding area & & 3.11 & 1.22 \\
\hline $\begin{array}{l}\text { Energy efficient } \\
\text { measures }\end{array}$ & Yes & Yes & $\begin{array}{l}\text { Environmental } \\
\text { friendly services } \\
\text { and infrastructure }\end{array}$ & & 2.65 & 1.73 \\
\hline
\end{tabular}

Figure 2, depicts the comparative satisfaction of the users on the selected urban development and environmental indicators. Network accessibility is the indicator with the highest performance in both interchanges, which denotes its modest support to the role in the network. Interchange time is valuated similarly in both cases, although the New Railway appears to host a shopping mall in the facility. However, both interchanges provide coffee shops and eateries, which apparently are most important, especially for travellers, who comprise almost $100 \%$ of the sample. In terms of environmental friendly services and infrastructure, the Intercity Coaches of Magnesia received higher mark than the New Railway, which is attributed to the targeted dissemination of the environmental policy of the first one to its customers, since there are no differences between the two interchanges, especially in terms of infrastructure operation. Finally, the surrounding area of the Intercity Coaches of Magnesia was rated higher, owing to the proximity of the interchange to the central city area, as compared to the New Railway. 


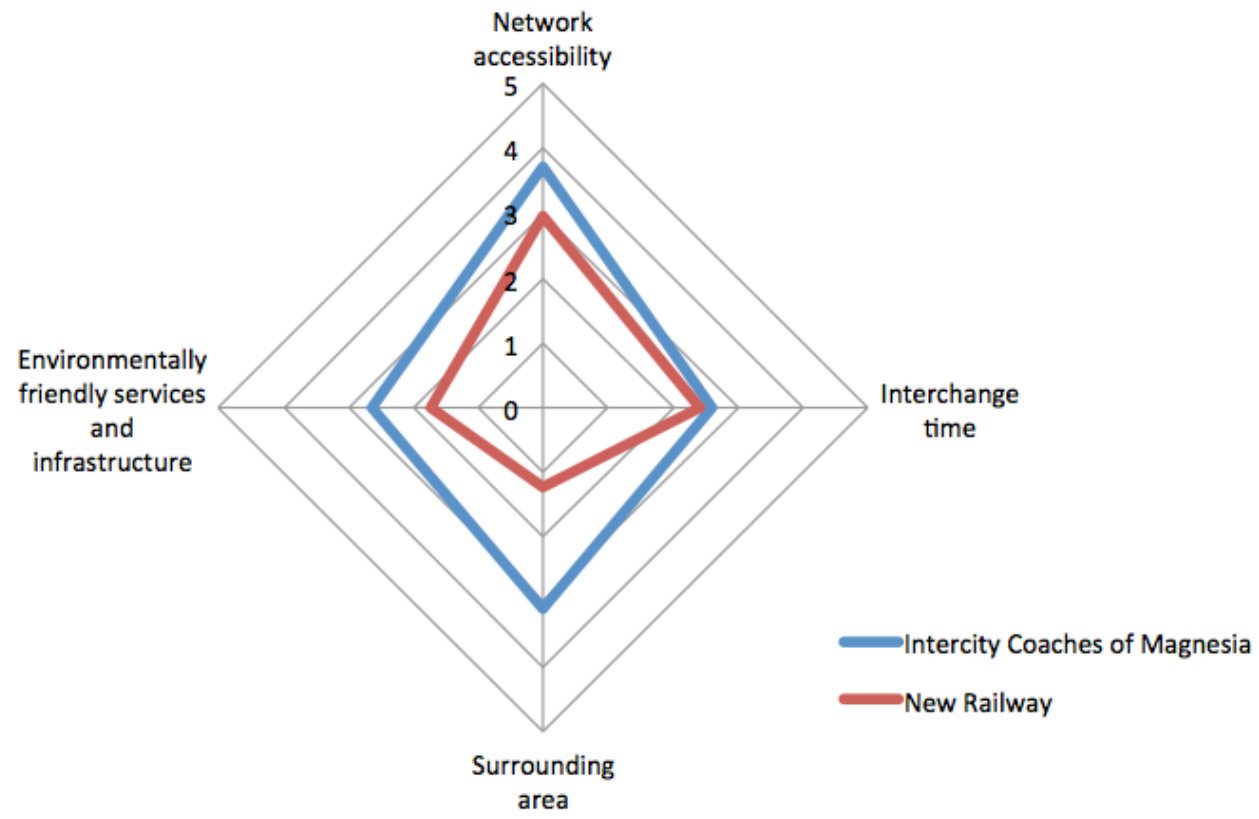

Figure 2. Comparative users' assessment of two interchanges

The individual indicators of the indicator categories, which were used for the valuation by the users of the interchange performance towards urban development and environment, are presented in the next paragraphs. The New Railway was selected for this presentation, as its performance was valuated lower than the Intercity Coaches of Magnesia.

The first indicator examined, was the network accessibility of the station through the available modes of travel, such as car, bus, taxi, etc. It is worth mentioning that for the majority of the respondents $(38 \%)$ the interchange is 5 to 10 kilometres away from their origin or destination, while $17 \%$ of them access the station in less than 5 kilometres. As presented in Figure 3, most of the respondents consider the network connection through bus $(80 \%)$ as above adequate and similarly they assess the taxi connection (67\%). Train, bicycle and walk network connections were assessed as not present in percentages 59\%, $57 \%$ and $51 \%$ respectively. Additionally, below adequate level was evaluated the connection by car $(53 \%)$.



Figure 3. Users' perception on network accessibility

Regarding the connection of the interchange with the wider urban area the opinion of the respondents was rather positive, owing to the advantageous location of the station (in close approximate with the city centre), and the high bus connectivity of the station with the majority of urban destinations, 
in this case. Thus, the majority of respondents consider that the connection of the interchange to the universities (71\%), the city centre (68\%), the Macedonia Bus Station (58\%) the City Hall (48\%), the airport $(48 \%)$, the central shopping centre $(47 \%)$, technical schools $(41 \%)$, and the port $(39 \%)$ is more than adequate (Fig. 4). The interchange's connection with hospitals (46\%) and the historic centre $(43 \%)$ was assessed as below adequate, mainly due to the fact that there is no direct connection with these destinations. Finally, the industrial area of Sindos seems not to be connected with the interchange for the $46 \%$ of the sample.

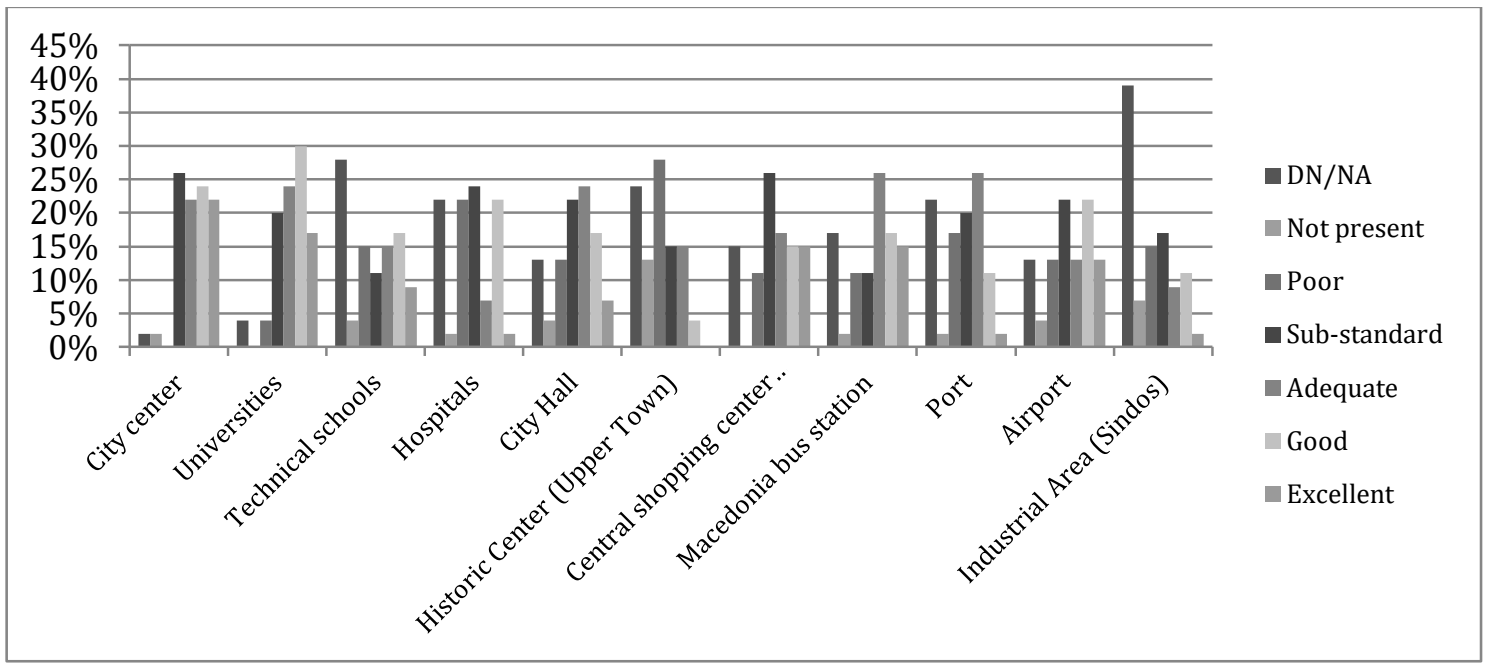

Figure 4. Users' perception on interchange connectivity with the wider urban area

Environmentally friendly services and infrastructures are mainly considered by respondents as not present (Fig. 5). Thus, they stated as non-existing, energy efficient infrastructure (91\%), power saving features $(89 \%)$, as no such infrastructure exists, green areas within the interchange $(80 \%)$ and green areas outside the interchange (67\%). They also noted that there are not any facilities promoting cycling $(74 \%)$ and walking (64\%). The rest of the users find below adequate the existence of recycle bins $(48 \%)$, facilities promoting walking (35\%), usage of recycle materials $(26 \%)$, green areas outside the interchange $(33 \%)$ and only some minor percentages (2-4\%) find above adequate recycle bins $(4 \%)$ and facilities promoting walking $(2 \%)$.

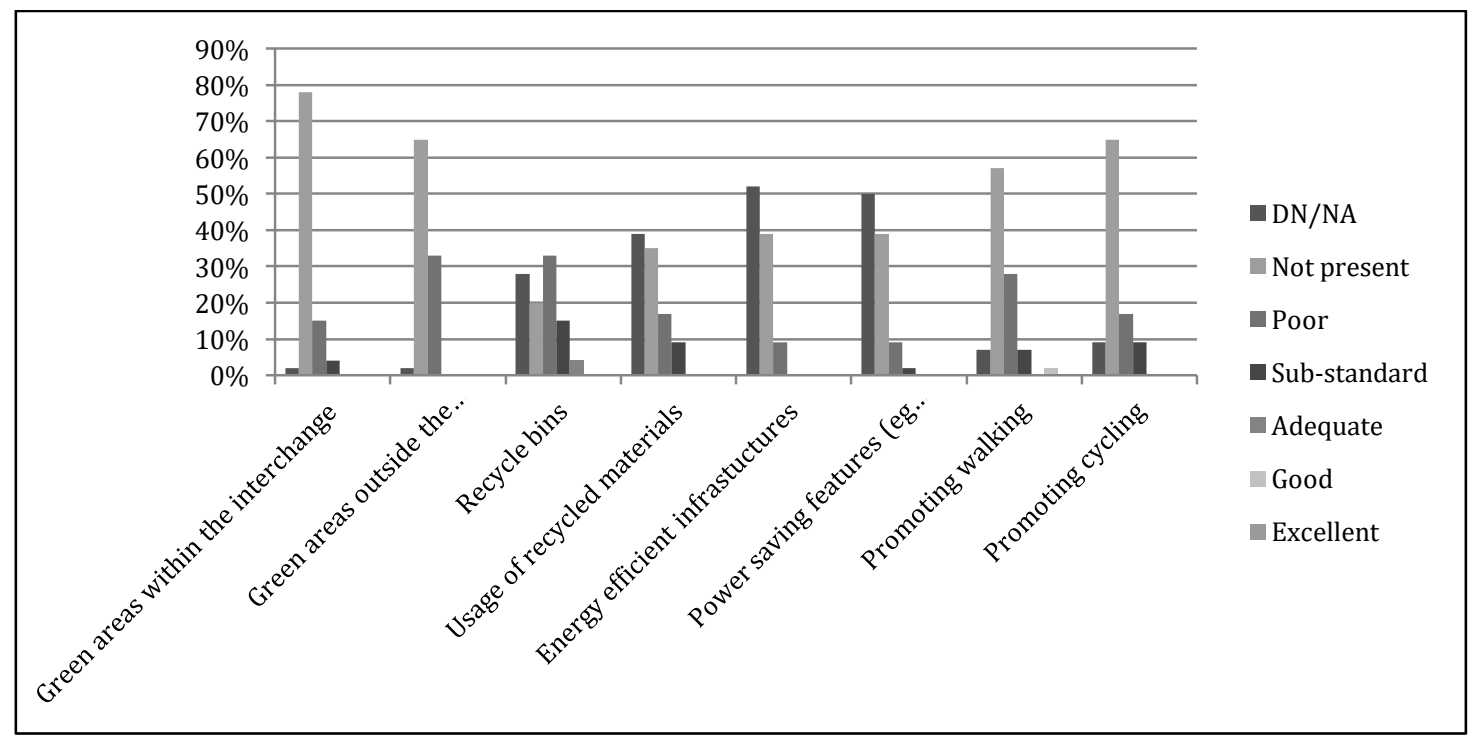

Figure 5. Users' perception on environmental friendly services and infrastructure 


\section{Conclusions and Recommendations}

Although national governments and local authorities make efforts to persuade travellers to switch mode, it seems that public transport still cannot be capable of competing with private car (Banister and Berechman, 2001). Based on the survey findings of this paper, the analysis showed that users addressed the low performance in the majority of indicators related to urban planning and environment, highlighting the need for a strategic plan of the interchanges, which was also revealed from the interviews with the stakeholders.

Urban transportation interchanges are considered as an important determinant of public transport with significant impacts on land uses, society, jobs' creation, housing and environment. However, in order to be able to enhance these impacts, a strong integrated development plan should be structured and implemented, including interchanges design aspects. Such a plan should enable the operation of "green" interchanges through:

- Integration with the rest of the network.

- Maximization of the seamlessness of the door-to-door travelling.

- Public transport connection prioritization.

- Harmonized regulatory frameworks for interconnections.

- Promoting sharing systems and service providers' cooperation.

- Security and safety provision for travellers and other users.

- Enhanced "green modes" (walk, bike, ride sharing) in terms of accessibility and fair and equal access to all.

- Reduced Greenhouse Gas emissions for all modes of the interchange and inclusion of environmental and other objectives in intermodal route planning.

- Maximization of "green energy" usage at the facility, subsidizing and promoting electromobility.

- Education, training, dissemination, promotion regarding efficient greener transport options.

A sustainable city-hub should be designed well harmonized with the urban space and under a resource-efficient, environmentally responsible and clean energy vision. Promoting electro mobility and/or alternative clean energy power for interchange operations could reduce substantially the carbon footprint. Moreover, increasing interchange attractiveness will bring more ridership to public transport modes, thus reduce private motorized traffic, promote greener transportation modes and reform city-hubs into true green urban interchanges.

\section{Acknowledgements}

This paper is based on the initial research conducted in the framework of the European project City-HUB (www.cityhub-project.eu), and the further work that has been made during the European project ALLIANCE (http://alliance-project.eu/). The authors would like to thank both the consortia of the projects and the European Commission.

\section{References}

1. Adamos, G., Tsami, M. and Nathanail, E. (2015) Urban interchanges: Moving towards a seamless transportation solution. $5^{\text {th }}$ International Conference on Environmental Management, Engineering, Planning and Economics (CEMEPE) and SECOTOX Conference. Mykonos Island, Greece, June 1418, 2015.

2. Banister, D. and Berechman, Y. (2001) Transport investment and the promotion of economic growth. Journal of Transport Geography, 9 (2001) 209-218.

3. City-HUB Project (2015) Deliverable D5.2: City-HUB Handbook.

4. Edwards, B. (2011) Transport interchanges: a challenge for urban design. Brian Edwards sets how interchanges must perform. Urban design-Autumn 2011-Issue 120.

5. European Commission (2001) White Paper "European transport policy for 2010: Time to decide".

6. European Commission (2006) Keep Europe Moving. Sustainable mobility for our continent. Midterm review of the European Commission's 2001 transport White Paper. ISBN 92-79-02312-8. Luxemburg: Office for Official Publications of the European Communities. 
7. European Commission (2011) Roadmap to a Single European Transport Area - Towards a competitive and resource efficient transport system. White Paper. COM (2011) 144 final. European Commission. Brussels, Belgium.

8. European Commission (2013) A concept for sustainable urban mobility plans, Annex I to the Communication from the Commission to the European Parliament, the Council, the European Economic and Social Committee and the Committee of the Regions. Together towards competitive and resource-efficient urban mobility. Annex I, COM (2013) 913 final.

9. European Communities (2009) Communication from the Commission to the European Parliament, the Council, the European Economic and Social Committee and the Committee of the Regions. Action Plan of Urban Mobility. COM (2009) 490 final. Brussels, Belgium.

10. Naude S., Joner J., Louw P. (2005) Design guidelines for public transport facilities. Available through: - http://repository.up.ac.za/bitstream/handle/2263/6332/041.pdf?sequence=1 [accessed on 07/02/2016].

11. PRESTO - "Promoting Cycling for Everyone as a Daily Transport Mode" was a project of the EU's Intelligent Energy - Europe Programme granted by the Executive Agency for Competitiveness and Innovation (EACI) running from 2009 until 2012.

12. Sintropher, (2012) Project report. Good practice in transport interchanges. A range of case studies from across the Northwest Europe area examining public transport interchange design. 